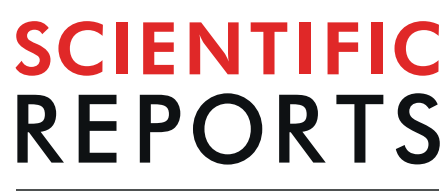

natureresearch

\title{
OPEN Close-up observations on the spawning behavior of a captive Japanese flying squid (Todarodes pacificus)
}

Jun Yamamoto ${ }^{1 *}$, Kohsuke Adachi' ${ }^{2}$, John R. Bower ${ }^{3}$, Hajime Matsui ${ }^{4,5}$, Mitsuhiro Nakaya ${ }^{3}$, Ryusei Ohtani ${ }^{6}$, Pandey Puneeta ${ }^{4}$, Satoshi Suzuki ${ }^{4,7}$, Shun Tokioka ${ }^{4,5}$, Dharmamony Vijai ${ }^{8}$, TakashiYanagimoto ${ }^{9}$ \& Hae-Kyun Yoo ${ }^{10}$

The spawning behavior of a Japanese flying squid (Todarodes pacificus) is described based on up-close observation of a captive female. The squid was first transferred from a 10-ton tank to a polystyrene plastic box containing 45 liters of seawater. About one hour later, the mantle-contraction rate increased rapidly, followed by a brief convulsion of the mantle and arms and a whitening of the body. The mantle contractions become shallow and rapid, and several seconds later, semitransparent jelly presumably from the nidamental glands emerged from the funnel and passed between the ventral pair of arms. Approximately 90 seconds after the egg mass first emerged, the female began ejecting oocytes through the funnel into the egg mass using rapid, powerful mantle contractions. Soon after the oocytes were ejected, translucent strands (presumably sperm) emanated from the buccal membrane. The female continued to eject oocytes for approximately two minutes, after which the mantle convulsed, and the mantle-contraction rate decreased slowly for about one minute until the contractions stopped. The squid died soon afterwards.

Cephalopod behavior is complex and has intrigued humans for centuries. Some of the most diverse behaviors are related to reproduction ${ }^{1}$. Our knowledge of cephalopod reproduction has grown much during the past two decades, but most of the research has focused on nearshore species, such as cuttlefishes and myopsid squids (reviewed by Hanlon and Messenger ${ }^{1}$ ), and idiosepiids (e.g., ${ }^{2,3}$ ); little is known about the oegopsid squids, which occur further offshore.

The Japanese flying squid (Todarodes pacificus) is a nerito-oceanic, ommastrephid species that occurs widely in continental shelf and slope waters in the northwest Pacific Ocean ${ }^{4}$. It is the target of the largest squid fishery in Japan and is usually one of the three largest cephalopod fisheries in the world ${ }^{5,6}$. The species undertakes a long-distance, southerly migration and spawns mainly during autumn and winter in the southwest Sea of Japan and northern East China Sea ${ }^{7}$.

The reproductive behavior of T. pacificus has not been observed in situ, but has been described based on laboratory studies ${ }^{8-10}$. During mating, a male deposits spermatophores onto a female's mouth (Fig. 1). The

${ }^{1}$ Field Science Center for Northern Biosphere, Hokkaido University, 3-1-1 Minato, Hakodate, Hokkaido, 041-8611, Japan. ${ }^{2}$ Faculty of Agriculture and Marine Science, Kochi University, Mononobe-otsu 200, Nankoku, Kochi, 7838502, Japan. ${ }^{3}$ Faculty of Fisheries Sciences, Hokkaido University, 3-1-1 Minato, Hakodate, Hokkaido, 041-8611, Japan. ${ }^{4}$ Graduate School of Fisheries Sciences, Hokkaido University, 3-1-1 Minato, Hakodate, Hokkaido, 0418611, Japan. ${ }^{5}$ Tohoku National Fisheries Research Institute, Japan Fisheries Research and Education Agency, $25-$ 259 Shimomekurakubo, Samemachi, Hachinohe, Aomori, 031-0841, Japan. ${ }^{6}$ Graduate School of Environmental Sciences, Hokkaido University, 3-1-1 Minato, Hakodate, Hokkaido, 041-8611, Japan. ${ }^{7}$ Shizuoka Prefectural Research Institute of Fishery, Izu Branch, 251-1 Shirahama, Shimoda, Shizuoka, 451-0012, Japan. ${ }^{8}$ National Centre for Biological Sciences, Tata Institute of Fundamental Research, Bellary Road, Bangalore, 560065, Karnataka, India. ${ }^{9}$ National Research Institute of Fisheries Science, Japan Fisheries Research and Education Agency, 2-12-4 Fukuura, Yokohama, Kanagawa, 236-8648, Japan. ${ }^{10}$ East Sea Fisheries Research Institute, National Institute of Fisheries Science, 1194, Haean-ro, Yeongok-myeon, Gangneung, Gangwon, 25435, Republic of Korea. *email: yamaj@fish. hokudai.ac.jp 


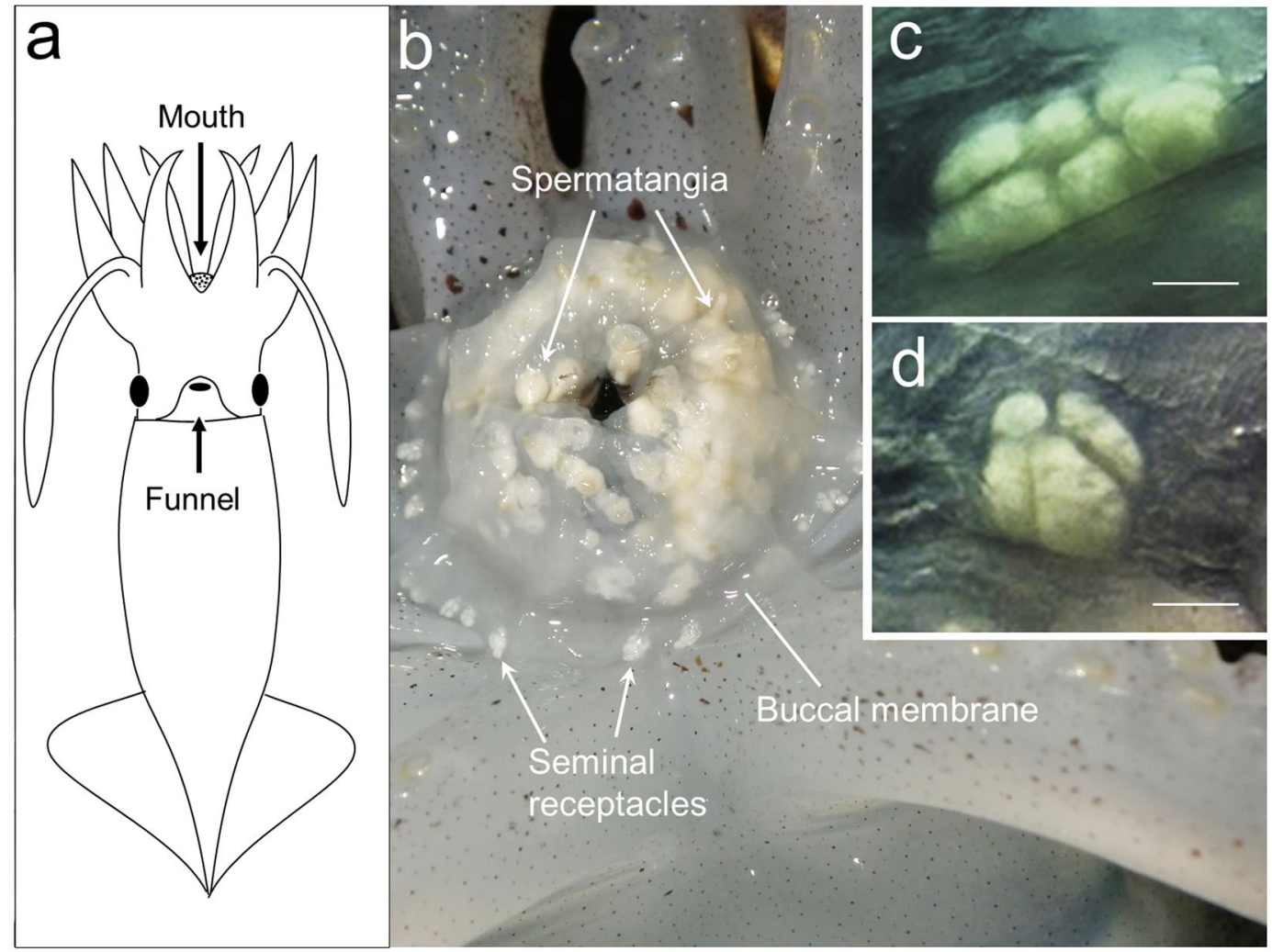

Figure 1. (a) Ventral view of a Japanese flying squid (Todarodes pacificus). (b) Mouth area of a copulated female before spawning. (c,d) Seminal receptacles, which usually comprise several sperm chambers. Bar $=0.5 \mathrm{~mm}$.

spermatophores release a sperm packet (spermatangium), which attaches to a ring of fleshy tissue surrounding the mouth called the lips ${ }^{11}$. Sperm then move from the embedded spermatangium to seminal receptacles located on the buccal membrane. This movement has not been observed in T. pacificus, but Soeda ${ }^{12}$ observed spermatozoa emanating from the distal ends of spermatangia embedded on the lip and speculated that mated females might manipulate the buccal membrane to bring the spermatangia tips near the sperm receptacles. In the ommastrephid Humboldt squid (Dosidicus gigas), sperm released from the spermatangia actively migrate across the buccal membrane to the seminal receptacles, where they are stored alive until the female spawns ${ }^{13}$.

In the females, oocytes (defined in the present paper as unfertilized female gametocytes) develop in the ovary and are released and stored in the oviducts. During spawning, the oocytes pass through the oviducal glands and are presumably coated with oviducal-gland secretions, allowing them to hydrate and preparing them for later chorionic expansion. The oocytes then pass through the funnel and into a gradually ballooning egg mass surrounded by a layer of jelly from the nidamental glands ${ }^{14}$. Fertilization is thought to occur near the buccal area as the oocytes enter the egg mass, however this process is unclear. What triggers the release of sperm from the seminal receptacles is also not known.

Despite our growing knowledge about the spawning behavior of T. pacificus, many questions remain unanswered, particularly related to the release and fertilization of oocytes. The present study was conducted to better understand these processes.

\section{Results}

Pre-spawning. The squid swam calmly after it was transferred to the box. The mantle-contraction rate was 65-70 per minute. Mantle chromatophores continuously pulsated.

Spawning. Approximately 64 minutes after the transfer, the mantle-contraction rate increased rapidly, followed by a brief convulsion of the mantle and arms. Chromatophores on the mantle and arms retracted, causing most of the body to whiten. The mantle contractions become shallower and more rapid (approximately 83 per minute). Immediately after the convulsion, jelly began to emerge from the funnel and pass between the ventral pair of arms (arms IV) (Fig. 2a). At first, the ventral arm pair (arms IV) were straight, but as the jelly started to extrude, the arms became bent. The other arms (I-III) and tentacles remained fairly straight. The jelly was semitransparent and contained no oocytes. It continued to slowly emerge, reaching near the buccal membrane (mouth) after about ten seconds and extending to near the tips of the dorsal arm pair (arms I) after another 70 seconds (see Supplementary Information Video 1).

Approximately 90 seconds after the egg mass first emerged (Fig. 2b), the female began ejecting oocytes through the funnel into the egg mass using rapid, powerful mantle contractions (approximately 120-125 per minute). The 


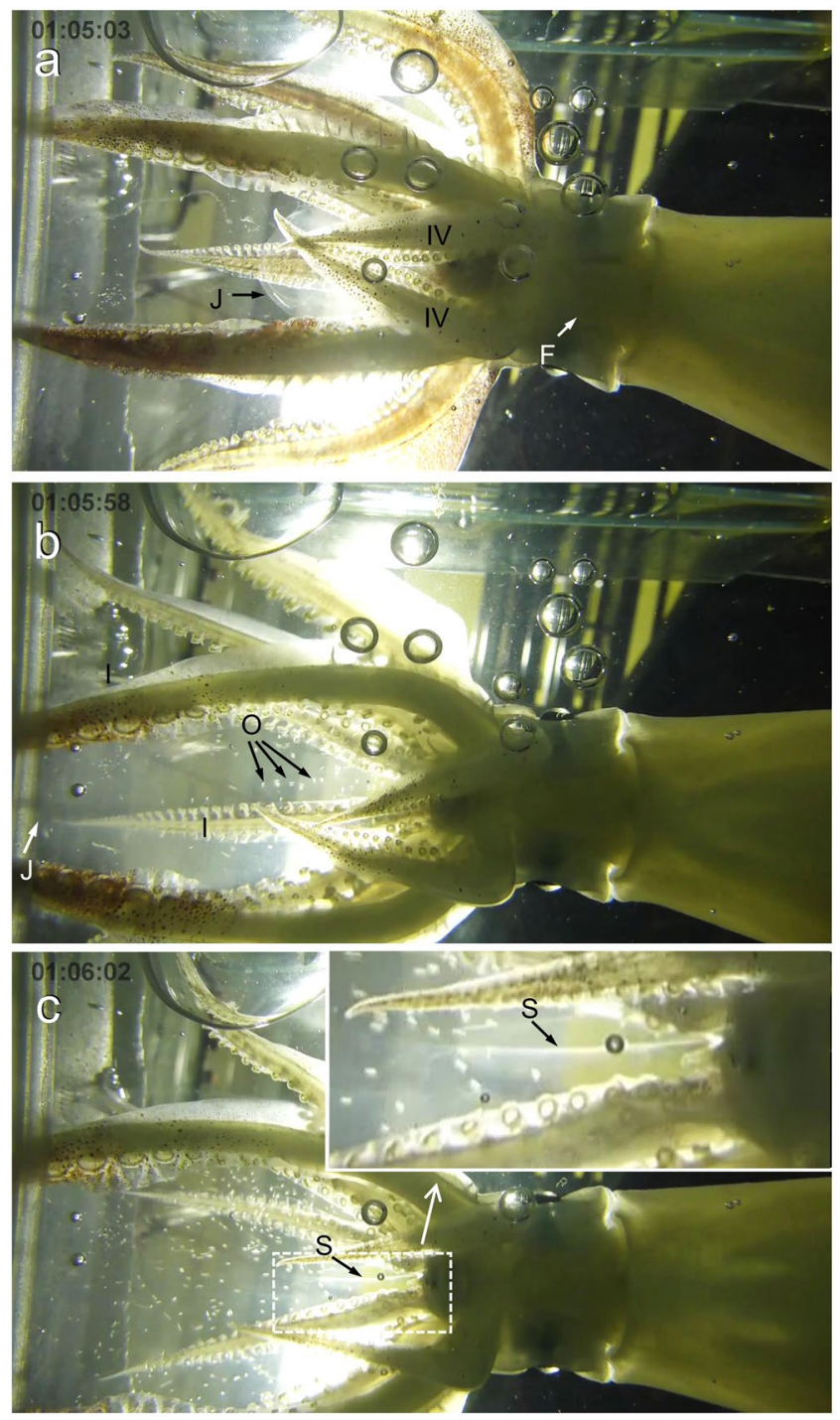

Figure 2. Stills from video of a spawning Japanese flying squid (Todarodes pacificus). (a) Squid slowly released cloudy but transparent jelly (J) through the funnel (F) and between the ventral pair of arms (arms IV). (b) When the jelly $(\mathrm{J})$ reached near the tips of the dorsal pair of arms (arms I), the squid began to eject oocytes (O). (c) The oocytes were pumped rapidly and vigorously over the buccal membrane. Filament-like translucent strands of presumably sperm (S) issued from the buccal membrane. Elapsed time after transfer to the box is shown in the upper left.

egg mass expanded for about ten seconds, but then broke apart, presumably due to the limited space inside the box. The female continued to eject oocytes for approximately two minutes. During this time, the oocytes were pumped vigorously over the buccal membrane causing the lips to flutter. Filament-like translucent strands of presumably sperm were seen issuing from the buccal membrane (Fig. 2c) (see Supplementary Information Video 2).

Two minutes after the start of spawning, the mantle convulsed, and the mantle-contraction rate decreased slowly for about one minute until the mantle contractions stopped.

Post-spawning. The squid stopped swimming after it ceased spawning and died within 20 minutes. Eggs were dispersed throughout the box. The number of eggs in the box were not counted, but visual estimates from video images indicate at least 2000 were spawned. Two days following the spawning, 98 eggs were randomly collected to estimate the fertilization rate. Approximately $29 \%$ were fertilized. Post-spawning dissection showed many oocytes remained in the oviducts, and spermatangia and seminal receptacles containing sperm remained near the mouth. The squid was classified as Stage V based the maturity scales of Lipinski and Underhill ${ }^{15}$.

\section{Discussion}

Our results are the first up-close observations on spawning in an oegopsid squid and provide several important clues about how oocytes are released and fertilized.

Spawning began with the gradual extrusion through the funnel of jelly, presumably from the nidamental glands, which contained no oocytes. This is the first direct observation of this phenomenon and supports 
Hamabe's ${ }^{16}$ suggestion that jelly extrusion precedes the discharge of oocytes. In his study, Hamabe kept mature females in barrels set on the seafloor and obtained egg masses and jelly. Based on these observations, he also suggested that the jelly adheres to substrate, which the results of our study and others do not support.

Soon after the squid began pumping oocytes into the egg mass, we observed what appeared to be sperm emanating from its buccal membrane. The ommastrephid squid D. gigas has circular muscles in its seminal-receptacle chambers, which may be used to extrude sperm ${ }^{13}$. A similar process could occur in T. pacificus, but what triggers this extrusion is not known. Durward et al. ${ }^{17}$ suggested that in the northern shortfin squid (Illex illecebrosus), an ommastrephid in which males implant spermatophores inside the female's mantle cavity instead of around the mouth, sperm are activated by the nidamental gland jelly. In a similar manner, chemical factors in the jelly extruded by T. pacificus before the release of oocytes could trigger the release of sperm from the seminal receptacles on the buccal membrane. This is a topic that warrants further investigation.

We were not able to confirm how fertilization occurs, but a spawning female might actively release spermatozoa from her seminal receptacles and insert them into the gradually ballooning egg mass as it emerges from the funnel. The powerful flow of water we observed over the buccal membrane would disperse the spermatozoa into and throughout the egg mass. Another possibility is that spermatozoa are released and actively swim toward and into the egg mass after passing through the outer egg-mass layer created from the nidamental-gland jelly. The mechanism guiding this movement is unclear, but other cephalopods are known to use chemical cues to direct the movement of sperm - a process called "sperm chemotaxis". In the common cuttlefish (Sepia officinalis), sperm-attracting peptides direct sperm to the oocytes ${ }^{18}$. Similarly, chemoattractant peptides in eggs of the common octopus (Octopus vulgaris) increase sperm motility and induce chemotaxis ${ }^{19}$. And in T. pacificus, sperm have been shown to attract to $\mathrm{CO}_{2}$, which could be emitted from oocytes ${ }^{20}$. Fernández-Álvarez et al. ${ }^{13}$ showed that in D. gigas, sperm in spermatangia implanted in the buccal membrane actively migrate over the surface of buccal membrane to the seminal receptacles, which suggests the seminal receptacles also release a sperm-attracting substance. We suspect the oocytes and possibly the nidamental gland jelly in T. pacificus also play a chemotaxic role in directing sperm toward the oocytes, but further experimental evidence is needed to confirm this hypothesis.

Previous studies (e.g., ${ }^{10,16,21}$ ) have suggested that fertilization occurs at or near the buccal membrane. Our observations on the vigorous pumping of oocytes past the buccal membrane and into the egg mass suggest the while sperm likely enter the egg mass near the buccal membrane, fertilization likely occurs deeper inside the egg mass. Each sperm released from the buccal area presumably has an equal chance or "fair raffle"22 in fertilizing a female's ova. Cryptic female choice could occur if females are able to manipulate sperm through controlled release from the sperm receptacles ${ }^{13}$, but this also requires further study. Furthermore, the outer jelly of the egg mass likely facilitates fertilization by protecting sperm and oocytes, and reducing sperm dispersal into the environment.

The pre-spawning squid did not display signs of extreme stress. First, after transfer to the box, the squid swam calmly and maintained a steady mantle-contraction rate for about one hour. And when spawning commenced, the female's ventral arms became bent similar to captive females that spawned in a large $\operatorname{tank}^{10}$, suggesting the female displayed normal spawning behavior. The observed pulsating chromatophores were also reported in previous studies in large tanks. Bower and Sakurai ${ }^{8}$ reported that about two days before spawning, the body chromatophores of pre-spawning females flash rapidly across the body surface in an incandescent pattern. This phenomenon was also reported by Puneeta et al. ${ }^{10}$. Conditions remained normal until the egg mass broke apart within the confined space. We believe the breaking apart of the egg mass was responsible for the low fertilization rate $(29 \%)$ compared with previous studies by Bower and Sakurai ${ }^{8}$ and Puneeta et al. ${ }^{10}$, who both reported fertilization rates within unbroken egg masses spawned in captivity above $90 \%$.

In conclusion, most of our knowledge of cephalopod reproduction has come from nearshore species that are accessible and that readily adapt to laboratory conditions. Oegopsid squids such as T. pacificus are more difficult to collect unharmed and rear long term for experiments like the one described in this paper. But to examine their reproductive behavior, laboratory studies are easier than studies at sea. Recent improvements in laboratory seawater systems and husbandry methods, as well as the creation of large experimental aquaria are creating more opportunities to study live cephalopod ${ }^{1,23}$, which we hope will help answer the many unresolved behavioral questions about reproduction in oceanic squids.

\section{Materials and Methods}

Squid. A total of 70 squid were collected on three dates during late August to mid-September 2016 by jigging aboard the Hokkaido University training vessel Oshoro maru in and around Tsugaru Strait (northern Japan) and transferred to an approximately 10-ton tank at the Hakodate Research Centre for Fisheries and Oceans, Japan (Hakodate). The squid were reared at $14-15^{\circ} \mathrm{C}$, during which they matured and mated. Mature females were visually identified by their enlarged oviducts (filled with amber-colored oocytes), nidamental glands, and oviducal glands, which became visible through the mantle while the squid swam in the tank.

Experimental design. On September 19th, a female (postmortem mantle length $=213 \mathrm{~mm}$, body weight $=233.1 \mathrm{~g}$ ) that appeared fully mature due to the large number of oocytes visible in its oviducts was removed from the tank and placed in a white, polystyrene, plastic (Styrofoam) box measuring $52 \times 32 \times 31 \mathrm{~cm}$ $(\mathrm{L} \times \mathrm{W} \times \mathrm{H})$ and filled with seawater from the tank. The date that this squid had been put in the tank was not known, but she had remained in the tank between 3 and 24 days. After the squid was introduced into the plastic box, the temperature was increased gradually to $20.3^{\circ} \mathrm{C}$ by adding $22.3^{\circ} \mathrm{C}$ seawater. The final volume of seawater in the box was ca. 45 liters. Captive experiments suggest T. pacificus females ovulate and spawn at $19-23^{\circ} \mathrm{C}^{24}$, so this $5-6^{\circ} \mathrm{C}$ increase in temperature was used as a thermal stimulant to induce spawning. A smaller glass tank was placed inside the box to maneuver the squid above a waterproof digital videocamera (DMC-FT5, Panasonic Corp., Japan) placed on the bottom of the box pointed upward. 
All procedures and experiments using squid were carried out in accordance with the "Guidelines for the Care and Welfare of Cephalopods in Research"25 and with the experimental guidelines set by Hokkaido University ${ }^{26}$.

\section{Data availability}

All data generated or analyzed during this study are included in this published article and its Supplementary Information Files (Video 1 and Video 2).

Received: 1 July 2019; Accepted: 15 November 2019;

Published online: 24 December 2019

\section{References}

1. Hanlon, R. T. \& Messenger, J. B. Cephalopod behaviour. (Cambridge University Press, New York, 1996).

2. Sato, N., Kasugai, T. \& Munehara, H. Sperm transfer or spermatangia removal: postcopulatory behaviour of picking up spermatangium by female Japanese pygmy squid. Mar. Biol. 160, 553-561, https://doi.org/10.1007/s00227-012-2112-5 (2013).

3. Iwata, Y. et al. How female squid inseminate their eggs with stored sperm. Curr. Biol. 29, R48-R49, https://doi.org/10.1016/j. cub.2018.12.010 (2019).

4. Roper, C. F. E., Nigmatullin, C. \& Jereb, P. Family Ommastrephidae in Cephalopods of the world. An annotated and illustrated catalogue of cephalopod species known to date. Volume 2. FAO species catalogue for fishery purposes. Vol. 2 (eds Jereb, P. \&Roper, C. F. E.) 269-347 (FAO, 2010).

5. Arkhipkin, A. I. et al. World squid fisheries. Reviews in Fisheries Science \& Aquaculture 23, 92-252 (2015).

6. FAO. The State of World Fisheries and Aquaculture 2018 - Meeting the sustainable development goals., Licence: CC BY-NC-SA 3.0 IGO (Rome, 2018).

7. Okutani, T. Todarodes pacificus in Cephalopod life cycles Vol. 1 (ed P. R. Boyle) 201-204 (Academic Press, London, 1983).

8. Bower, J. R. \& Sakurai, Y. Laboratory observations on Todarodes pacificus (Cephalopoda: Ommastrephidae) egg masses. Am. Malacol. Bull. 13, 65-71 (1996).

9. Sakurai, Y., Bower, J. \& Ikeda, Y. Reproductive characteristics of the ommastrephid squid Todarodes pacificus. Fisken Havet 12, $105-115$ (2003).

10. Puneeta, P., Vijai, D., Yoo, H. K., Matsui, H. \& Sakurai, Y. Observations on the spawning behavior, egg masses and paralarval development of the ommastrephid squid Todarodes pacificus in a laboratory mesocosm. J. Exp. Biol. 218, 3825-3835, https://doi. org/10.1242/jeb.127670 (2015).

11. Ikeda, Y., Sakurai, Y. \& Shimazaki, K. Fertilizing capacity of squid (Todarodes pacificus) spermatozoa collected from various sperm storage sites, with special reference to the role of gelatinous substance from oviducal gland in fertilization and embryonic development. Invertebr. Reprod. Dev. 23, 39-44 (1993).

12. Soeda, J. Studies on the ecology and the breeding habits of the squid, Ommastrephes sloani pacificus (Steenstrup). Bull. Hokkaido Reg. Fish. Res. Lab 14, 1-24. (in Japanese with English abstract) (1956).

13. Fernandez-Alvarez, F. A., Villanueva, R., Hoving, H. J. T. \& Gilly, W. F. The journey of squid sperm. Rev. Fish. Biol. Fish 28, 191-199, https://doi.org/10.1007/s11160-017-9498-6 (2018).

14. Nesis, K. N. Cephalopods of the world: squids, cuttlefishes, octopuses and allies. Translated from Russian by B.S. Levitov. (ed. Burgess, L.A.). (TFH Publications, Neptune City, NJ, 1987).

15. Lipiński, M. \& Underhill, L. Sexual maturation in squid: quantum or continuum? S Afr. J. Mar. Sci. 15, 207-223 (1995).

16. Hamabe, M. Embryological studies on the common squid Ommastrephes sloani pacificus Steenstrup, in the southwestern waters of the Sea of Japan. Bull. Jpn. Sea Reg. Fish Res. Lab. 10, 1-45 (in Japanese with English abstract) (1962).

17. Durward, R., Vessey, E., O'Dor, R. \& Amaratunga, T. Reproduction in the squid, Illex illecebrosus: first observations in captivity and implications for the life cycle. Sel. Pap. ICNAF 6, 7-13 (1980).

18. Zatylny, C., Marvin, L., Gagnon, J. \& Henry, J. Fertilization in Sepia officinalis: the first mollusk sperm-attracting peptide. Biochem. Biophys. Res. Commun. 296, 1186-1193, https://doi.org/10.1016/s0006-291x(02)02036-3 (2002).

19. De Lisa, E., Salzano, A. M., Moccia, F., Scaloni, A. \& Di Cosmo, A. Sperm-attractant peptide influences the spermatozoa swimming behavior in internal fertilization in Octopus vulgaris. J. Exp. Biol. 216, 2229-2237, https://doi.org/10.1242/jeb.081885 (2013).

20. Hirohashi, N., Iida, T., Sato, N., Warwick, S. H. H. \& Iwata, Y. Complex adaptive traits between mating behaviour and postcopulatory sperm behaviour in squids. Rev. Fish. Biol. Fish 26, 601-607, https://doi.org/10.1007/s11160-016-9434-1 (2016).

21. Hanlon, R. T., Vecchione, M. \& Allcock, L. Octopus, squid \& cuttlefish. A visual, scientific guide to the oceans' most advanced invertebrates. (The University of Chicago Press, 2018).

22. Parker, G. A. Sperm Competition Games - Raffles and Roles. P. Roy. Soc. B-Biol. Sci. 242, 120-126, https://doi.org/10.1098/ rspb.1990.0114 (1990).

23. Boal, J. G. Behavioral Research Methods for Octopuses and Cuttlefishes. Vie Milieu. 61, 203-210 (2011).

24. Sakurai, Y. et al. Todarodes pacificus. Japanese common squid. In Advances in Squid Biology, Ecology and Fisheries. Part II-Oegopsid Squids (eds Rosa, R., Pierce, G. \& O’Dor, G.) 249-272 (Nova Science Publishers, New York, 2013).

25. Fiorito, G. et al. Guidelines for the Care and Welfare of Cephalopods in Research-A consensus based on an initiative by CephRes, FELASA and the Boyd Group. Lab. Anim. 49, 1-90 (2015).

26. Hokkaido University. National University Corporation Hokkaido University Provisions on Animal Experiments. HU Doc. No. 61. https://www.global.hokudai.ac.jp/rules-and-regulations-for-check/ [Research Related, No. 06] (2007).

\section{Acknowledgements}

We thank the captain and crew of the T/S Oshoro maru for their help collecting squid. This work was partly supported by JSPS KAKENHI Grant Number 16H04963.

\section{Author contributions}

J.Y. designed and oversaw the study. H.M., S.S., and S.T. conducted the experiments. H.M. analyzed the video data. J.Y., K.A. M.N., R.O., T.Y., and H.-K.Y. drafted the manuscript. J.Y., J.R.B., P.P. and D.V. revised the manuscript. All authors have reviewed and approved the content of the manuscript.

\section{Competing interests}

The authors declare no competing interests.

Additional information

Supplementary information is available for this paper at https://doi.org/10.1038/s41598-019-56071-0. 
Correspondence and requests for materials should be addressed to J.Y.

Reprints and permissions information is available at www.nature.com/reprints.

Publisher's note Springer Nature remains neutral with regard to jurisdictional claims in published maps and institutional affiliations.

(c) Open Access This article is licensed under a Creative Commons Attribution 4.0 International License, which permits use, sharing, adaptation, distribution and reproduction in any medium or format, as long as you give appropriate credit to the original author(s) and the source, provide a link to the Creative Commons license, and indicate if changes were made. The images or other third party material in this article are included in the article's Creative Commons license, unless indicated otherwise in a credit line to the material. If material is not included in the article's Creative Commons license and your intended use is not permitted by statutory regulation or exceeds the permitted use, you will need to obtain permission directly from the copyright holder. To view a copy of this license, visit http://creativecommons.org/licenses/by/4.0/.

(C) The Author(s) 2019 